\title{
Promoter analysis of the SPATULA (FvSPT) and SPIRAL (FvSPR) genes in the woodland diploid strawberry (Fragaria vesca L.)
}

\author{
Norbert Hidvégi $^{1}{ }^{\mathbb{D}} \cdot$ Andrea Gulyás $^{1} \cdot$ Jaime A. Teixeira da Silva ${ }^{1,2} \cdot$ Adhityo Wicaksono $^{3} \cdot$ Erzsébet Kiss $^{4}$
}

Received: 28 May 2020 / Accepted: 7 May 2021 / Published online: 9 June 2021

(c) The Author(s) 2021

\begin{abstract}
The aim of this study was to identify transcription factor (TF) binding sites and cis-regulatory elements (CREs) on the promoters of FvSPRI-like2 (SPIRAL) and FVSPT (SPATULA) genes in the woodland diploid strawberry (Fragaria vesca L.). We identified: (1) MYB59, WRKY25 and WRKY8 TFs which play a role in ethylene signaling; (2) ARF family of TFs which play a role in ARF-mediated auxin signaling on the promoter of FvSPRI-like2 gene; (3) ARR family of TFs which play a role in cytokinin signaling; (4) ERF family of TFs which play a role in ethylene signaling on the promoter of $F v S P T$. This bioinformatic analysis of TFs and CREs may provide a better understanding of the function of genes involved in, and the mechanism underlying, non-climateric ripening during strawberry fruit maturation.
\end{abstract}

Keywords Agroinfiltration · Cis-regulatory elements $\cdot$ SPATULA $\cdot$ SPIRAL $\cdot$ Transient gene expression · Transcription factors

\section{Introduction}

Members of the SPR gene family encode small proteins that contribute to cell elongation by regulating microtubule organization (Nakajima et al. 2004). SPR genes in A. thaliana are classified into two main groups, $S P R 1$ and $S P R 2$ (Bichet et al. 2001; Burk and Ye 2002), and five subgroups, SPR1-like1 to SPR1-like5, all of which have been functionally characterized (Nakajima et al. 2004).

Norbert Hidvégi

hidvegi.norbert@agr.unideb.hu

$\square$ Erzsébet Kiss

kiss.erzsebet@mkk.szie.hu

1 Centre for Agricultural Genomics and Biotechnology, Faculty of Agricultural and Food Science and Environmental Management, University of Debrecen, P.O. Box 12, Nyíregyháza 4400, Hungary

2 Independent Researcher, Miki-cho post office, Ikenobe 3011-2, P. O. Box 7, Kagawa-ken 761-0799, Japan

3 Division of Biotechnology, Generasi Biologi Indonesia Foundation, Jl. Swadaya Barat no. 4, Gresik Regency 61171, Indonesia

4 Institute of Genetics, Microbiology and Biotechnology, Faculty of Agricultural and Environmental Sciences, Hungarian University of Agriculture and Life Sciences, Páter Károly u. 1, 2100 Gödöllő, Hungary
The $S P R$ gene influences the elongation and development of plants at both cellular and organ levels (Furutani et al. 2000; Nakajima et al. 2004). Furutani et al. (2000) induced a mutant $S P R$ gene in A. thaliana whose roots curved to the right unlike control roots that grew straight. The mutation resulted from the arrangement of cortical microtubules on the opposite side of the optimal direction in epidermal root cells, also effecting helical handedness. Overexpression of the $S P R$ gene did not stimulate root skewing since its main function is to maintain the straight elongation of root cells. In addition, the $S P R$ gene enhanced the rapid elongation of cells, resulting in the lengthwise enlargement of tissues. Moreover, SPR genes interact with cellular molecules to control anisotropic growth (Nakajima et al. 2004).

The SPT transcription factor positively indicates and controls cytokinin output in the medial region of the ovary (Reyes-Olalde et al. 2017a). The SPT gene regulates auxin signaling in gynoecium and style-sigma development (Moubayidin and Ostergaard 2014; Schuster et al. 2015). The $S P T$ gene is expressed in non-climacteric strawberry (Fragaria $\times$ ananassa Duch.) when treated with auxin and ethylene and is regulated by four ethylene responsive elements (EREs) in the SPT promoter region (Tisza et al. 2010).

Transcriptional regulation of gene expression is fundamental to biological processes, such as cell growth, development, differentiation, fruit ripening and responses to 
environmental signals (Meshi and Iwabuchi 1995). Given its importance as a transcriptional regulator of genes, the analysis of plant promoters may provide important information that would better guide the construction of biotechnological systems because regulated gene expression systems can increase the function of genetically modified organisms (Corrado and Karali 2009). As internal physiological control regulators, plant hormones also have important roles in the transcriptional regulation of genes, such as development and fruit ripening (An et al. 2020), for example, ethylene and auxin control different steps of the flower-to-fruit transition (Bapat et al. 2010; Kumar et al. 2014; Ziliotto et al. 2012). An antagonistic effect can be observed between ethylene and auxin during tomato fruit ripening ( $\mathrm{Li}$ et al. 2017).

In this study, tomato (Solanum lycopersicum L.) cv. Micro-Tom and tobacco (Nicotiana benthamiana) were selected as model plants, as these plants are often chosen in genetic studies to examine and observe differences in gene expression using the green fluorescence protein (GFP) marker gene (Hoshikawa et al. 2019; Reed and Osbourn 2018). Agrobacterium tumefaciens-mediated transfer, together with an agroinfiltration (also known as agroinjection) method, was used in this study. Agroinfiltration is an Agrobacterium-mediated transient recombinant protein expression method which can be used to avoid labor-intensive and time-consuming methods to produce stable transgenic plants (Hoshikawa et al. 2019). Infiltration is achieved by delivering the Agrobacterium with the target genes into extracellular leaf space by physical infiltration (Norkunas et al. 2018). Physical infiltration in this study was performed with a needleless syringe.

The aim of this study was to characterize the $S P T$ and $S P R$ gene promoters which were isolated from Fragaria vesca $\mathrm{L}$., the woodland diploid strawberry, by finding specific motifs. The putative promoter region was identified with the JASPAR 2020 plantae algorithm (Fornes et al. 2020) for TFs as well as a promoter motifs database (http://jaspar.genereg.net/) allowing us to predict the promoter regions of the tomato (Solanum lycopersicum L.) cv. Micro-Tom SPT, SPRI-like2 (MtSPT and MtSPRIlike2), as well as $F$. vesca SPT, SPR1-like1 and SPR1-like2 (FvSPT, FvSPR1-like1 and FvSPR1-like2) genes, which show selective complementation in A. thaliana (Hidvégi et al. 2020). We compared these promoter sequences with promoters of A. thaliana SPT and SPRI-like2 (AtSPT and AtSPR1-like2) reference genes. Moreover, we used PCR amplification of different lengths of upstream regions of the FvSPT and FvSPRI-like 2 coding sequences and insertion of putative promoter fragments into a binary vector (pGWB604) carrying the $s G F P$ reporter gene. Tomato and tobacco were agroinjected with the pGWB604 and pGWB405 (CaMV35S::sGFP, as positive control) binary vectors that included a fusion of the promoter deletion lines and the sGFP reporter gene. Promoter deletion lines can be used to identify the presence of genetic regulatory elements (TFs or CREs) such as enhancers and silencers in the region upstream of the start codon.

\section{Materials and methods}

\section{Plant materials and growth conditions}

Diploid strawberry (Fragaria vesca 'Rügen') was used as the template to amplify the putative promoter regions of FvSPT and FvSPR1-like2. Seeds of tomato (cv. MicroTom), diploid strawberry and tobacco (Nicotiana benthamiana) were sown ex vitro in $50 \mathrm{~mm}$ Jiffy-7® pots $(1 \mathrm{seed} /$ pot). Jiffy pots were placed in a climate room at $22{ }^{\circ} \mathrm{C}$ and kept under an 8-h photoperiod at a photosynthetic photon flux density (PPFD) of $37 \mu \mathrm{mol} \mathrm{m} \mathrm{m}^{-2} \mathrm{~s}^{-1}$ provided by Biolux tubes (Osram L58W, Markham, Canada). When seedlings formed two fully developed leaves, rooted plantlets were transferred to plastic pots $(9 \mathrm{~cm})$ into soil and grown under the same conditions as seedlings. No fertilizers or additional supplements (e.g., pest control agents) were added.

\section{Computational analysis of promoters}

The S. lycopersicum genome was studied in silico based on the Tomato Genome Consortium (2012) wholegenome sequences for promoters of MtSPT (Gene ID: 101,266,791, NC_015439.3) and MtSPRI-like2 (Gene ID: $101,257,849$, NC_015440.3) genes. The $F$. vesca Whole Genome v2.0a1 assembly \& annotation (http://www. rosaceae.org) was used to analyze in silico the promoters of FvSPT (XM_004287975; LOC101290893), FvSPR1like1 (XM_004297177; LOC01307108) and FvSPRI-like2 (XM_004299243; LOC101309836) genes. We used the A. thaliana whole-genome assembly (Swarbreck et al. 2007) as the reference for the promoters of AtSPT (BT024676) and AtSPRl-like2 (BT026462) genes.

The promoters of FvSPR1-like1, FvSPR1-like 2 and $F v S P T$ genes were isolated and aligned with the A. thaliana and S. lycopersicum sequences by using NCBI BLAST (https://blast.ncbi.nlm.nih.gov/Blast.cgi) analysis to find similarities or homologies. The promoter regions of the genes were examined with JASPAR 2020 (Fornes et al. 2020) and PLACE 30.0 (database of plant cis-acting regulatory DNA elements; Higo et al. 1999) to determine the transcriptional factor binding sites (TFBS) and CREs to develop promoter deletion lines of promoters of FVSPRI-like 2 and FvSPT genes. 


\section{PCR amplification of promoter deletion lines}

The sequences upstream (from the start codon) of the FvSPT gene (3100 bp, XM_004287975; LOC101290893) and the FvSPRI-like2 gene (2800 bp, XM_004299243; LOC101309836) were amplified. PCR amplification was performed in FvSPRI-like 2 and FvSPT promoter genes to yield 500 bp (FvSPR500, FvSPT500), 1000 bp (FvSPR1000, FvSPT1000), 2000 bp (FvSPR2000, FvSPT2000) and 3000 bp (FvSPT3000) fragments. PCR amplification was performed with the GoTaq Long PCR Master Mix (Promega, Madison, WI, USA). Genomic DNA (100 ng) was used as template DNA in a 50- $\mu \mathrm{L}$ PCR mix. The PCR mixture consisted of $25 \mu \mathrm{L}$ of GoTaq Long PCR Master Mix (2x) and 30 pmol of each primer (Suppl. Table 1). PCR conditions, optimized in-house, were: $95^{\circ} \mathrm{C}$ for 2 min followed by 35 cycles at $95{ }^{\circ} \mathrm{C}$ for $30 \mathrm{~s}, 65^{\circ} \mathrm{C} 1 \mathrm{~min}(500 \mathrm{bp}$ and $1000 \mathrm{bp}$ promoter deletion lines) or 3 min (2000 bp and 3000 bp promoter deletion lines). Cycling was followed by a final incubation at $72{ }^{\circ} \mathrm{C}$ for $10 \mathrm{~min}$. PCR products were separated on $1.0 \%$ agarose gels in $1 \times$ TAE buffer (Sambrook et al. 1989) by agarose gel electrophoresis and detected by fluorescence under UV light (302 nm) with a VWR ${ }^{\circledR}$ Smart3 Gel documentation system (VWR International, Radnor, PA, USA) after staining with $0.1 \%$ ethidium bromide (IBI Scientific, Dubuque, IA, USA).

\section{$\mathrm{TOPO}^{\circledR}$ and gateway ${ }^{\circledR}$ LR cloning}

FvSPT500, FvSPT1000, FvSPT2000, and FvSPT3000 from $F v S P T$ and FvSPR500, FvSPR1000, and FvSPR2000 from $F v S P R$ were cloned by directional cloning using the pENTR $^{\text {TM }}$ Directional TOPO ${ }^{\circledR}$ vector based on the Invitrogen pENTR ${ }^{\mathrm{TM}}$ Directional TOPO ${ }^{\circledR}$ Cloning Kit manual (Invitrogen, Carlsbad, CA, USA). One Shot ${ }^{\circledR}$ TOP10 chemically competent Escherichia coli cells (Invitrogen) were transformed with constructed TOPO vectors according to the One-Shot Chemical transformation protocol (Invitrogen pENTR ${ }^{\mathrm{TM}}$ Directional TOPO ${ }^{\circledR}$ Cloning Kit manual, Invitrogen). The E. coli was grown on Luria-Bertani (LB) media (Bertani 1951) with $100 \mathrm{mg} / \mathrm{mL}$ kanamycin (Duchefa, Haarlem, the Netherlands). To select positive clones of putative promoter regions, colony PCR and agarose gel electrophoresis was applied using the same conditions employed for PCR amplification of promoter deletion lines. Colony PCR used M13 universal primer (Invitrogen pENTR ${ }^{\mathrm{TM}}$ Directional TOPO ${ }^{\circledR}$ Cloning Kit manual, Invitrogen). E. coli colonies carrying the inserted promoter region were grown overnight on LB plates with $100 \mathrm{mg} /$ $\mathrm{mL}$ kanamycin and transferred with toothpicks to $5 \mathrm{~mL}$ of LB media containing $5 \mu \mathrm{L}$ kanamycin $(100 \mathrm{mg} / \mathrm{mL})$ and grown on a shaker $\left(140 \mathrm{rpm}\right.$ at $37^{\circ} \mathrm{C}$, overnight). Plasmid
DNA from competent E. coli was isolated and purified by the Pure Yield ${ }^{\text {TM }}$ Plasmid Miniprep Kit (Promega, Madison, WI, USA) based on the manufacturer's user manual. Gateway ${ }^{\circledR}$ LR Clonase ${ }^{\mathrm{TM}}$ II enzyme Mix (Invitrogen) was used for pGWB604 plasmid (Nakagawa et al. 2007; GenBank: AB543113.1) construction as the binary destination vector which contains the synthetic green fluorescent protein marker gene ( $s G F P$; Niwa 2003). The pGWB405 (Nakagawa et al. 2007; GenBank: AB294429.1) vector, which contains the CaMV35S promoter with $s G F P$, was used as the positive control for transient gene expression. The FvSPR500::pGWB604, FvSPR1000::pGWB604, FvSPR 2000::pGWB604, FvSPT500::pGWB604, FvSPT1000::pGWB604, FvSPT2000::pGWB604 and FvSPT3000::pGWB604 vector constructs were built by cloning.

\section{Agrobacterium-mediated transformation}

Agrobacterium tumefaciens GV3101 strain (Intact Genomics, Creve Coeur, MI, USA) was incubated in an LB plate with a working concentration of $10 \mu \mathrm{g} / \mathrm{mL}$ gentamycin $\left(10 \mathrm{mg} / \mathrm{mL}\right.$ stock; Duchefa) at $28^{\circ} \mathrm{C}$ for $2 \mathrm{~d}$. A single colony of A. tumefaciens from the LB plate was incubated in $5 \mathrm{~mL}$ of liquid LB with $5 \mu \mathrm{L}$ of spectinomycin $(50 \mathrm{mg} / \mathrm{mL}$ stock; Duchefa) and $5 \mu \mathrm{L}$ of gentamycin $(10 \mathrm{mg} / \mathrm{mL}$ stock) overnight in a MaxQ 4000 Benchtop Orbital Shaker (ThermoFischer Scientific, Waltham, MA, USA) at $140 \mathrm{rpm}$ and $28^{\circ} \mathrm{C}$. Cultures were placed on ice for $30 \mathrm{~min}$ then centrifuged for $10 \mathrm{~min}$ at $4000 \mathrm{rpm}$ and at $4{ }^{\circ} \mathrm{C}$. The supernatant was discarded, and the pellet was resuspended in $5.0 \mathrm{~mL}$ of $20 \mathrm{mM}$ $\mathrm{CaCl}_{2}$ on ice then centrifuged again for $5 \mathrm{~min}$ at $4000 \mathrm{rpm}$ and $4{ }^{\circ} \mathrm{C}$. The supernatant was discarded and $1.0 \mathrm{~mL}$ of icecold $20 \mathrm{mM} \mathrm{CaCl}{ }_{2}$ was added to the pellet in ice water. A $200 \mu \mathrm{L}$ aliquot as competent $A$. tumefaciens cells was prechilled in $1.5-\mathrm{mL}$ microcentrifuge tubes (Eppendorf, Hamburg, Germany). Plasmid DNA ( $3 \mu \mathrm{L} ; 500 \mathrm{ng}$ ) was added from the pGWB604 vector containing the promoter region into each tube containing competent $A$. tumefaciens cells and kept on ice for $20 \mathrm{~min}$, placed in liquid nitrogen for $5 \mathrm{~min}$, heat shocked at $37^{\circ} \mathrm{C}$ for $5 \mathrm{~min}$, then added to ice for 5 min. Liquid LB media $(1.0 \mathrm{~mL})$ was added to each heatshocked colony and incubated in a shaker at $28{ }^{\circ} \mathrm{C}$ and at $140 \mathrm{rpm}$ for 3-4 h. Sample (100-150 $\mu \mathrm{L})$ was pipetted onto an LB plate supplemented with $10 \mu \mathrm{g} / \mathrm{mL}$ of gentamycin $(10 \mathrm{mg} / \mathrm{mL}$ stock) and $50 \mu \mathrm{g} / \mathrm{mL}$ of spectinomycin $(50 \mathrm{mg} /$ $\mathrm{mL}$ stock). Based on the Bergkessel and Guthrie (2013) protocol, colony PCR was performed to confirm the success of transformation using the same conditions used for TOPO ${ }^{\circledR}$ and Gateway ${ }^{\circledR}$ LR cloning. 


\section{Agroinfiltration in tomato and tobacco}

A single A. tumefaciens colony was cultured in $5 \mathrm{~mL}$ of LB medium supplemented with $5 \mu \mathrm{L}$ gentamycin $(10 \mathrm{mg} /$ $\mathrm{mL}$ stock) and $5 \mu \mathrm{L}$ spectinomycin $(50 \mathrm{mg} / \mathrm{mL})$ overnight at $28{ }^{\circ} \mathrm{C}$ on a shaker at $140 \mathrm{rpm}$. Cultures were transferred to $50 \mathrm{~mL}$ of induction medium $\left(10.5 \mathrm{~g} \mathrm{~K}_{2} \mathrm{HPO}_{4}, 4.5 \mathrm{~g} \mathrm{KH}_{2} \mathrm{PO}_{4}\right.$, $1 \mathrm{~g}\left(\mathrm{NH}_{4}\right)_{2} \mathrm{SO}_{4}, 0.5 \mathrm{~g}$ Na-citrate, $1 \mathrm{~g}$ glucose, $1 \mathrm{~g}$ fructose, $4 \mathrm{~mL}$ glycerol, $0.12 \mathrm{~g} \mathrm{MgSO}_{4}, 1.95 \mathrm{~g}$ MES $(10 \mathrm{mM}) ; \mathrm{pH}$ 5.6; Singer et al. 2012) containing $100 \mu \mathrm{M}$ acetosyringone (Duchefa), which was added after autoclaving $\left(121^{\circ} \mathrm{C}\right.$, $60 \mathrm{~min}$ ). Cells were incubated in induction medium at $30{ }^{\circ} \mathrm{C}$ for $5-6 \mathrm{~h}$ at $140 \mathrm{rpm}$. After incubation, cells were centrifuged at $4000 \mathrm{rpm}$ for $10 \mathrm{~min}$, and then the pellet was resuspended in infiltration medium $\left(10 \mathrm{mM} \mathrm{MgSO}_{4}\right.$, 10 mM MES; pH 5.6; Singer et al. 2012) supplemented with $200 \mu \mathrm{M}$ acetosyringone. Green and ripening tomato fruits (age: about $60 \mathrm{~d}$ after germination; sample number: 20 fruits/vector construct, 2 fruits/plant) and tobacco leaves (age: about $45 \mathrm{~d}$ after sowing; sample number: 20 leaves/ vector construct, 2 leaves/plant) were agroinjected by using a $1 \mathrm{~mL}$ syringe (Z683531; Sigma-Aldrich, St. Louis, MI, USA) with a $0.5 \times 1.6 \mathrm{~mm}$ needle (Sigma-Aldrich). Infiltration solution was injected (5-6 $\mathrm{mm}$ deep) into tomato fruit through stylar apex, while leaves were injected by slightly injuring the epithelium tissue of the abaxial surface. Plants were tested 3 d later with the Phire Plant Direct PCR Kit (ThermoFischer Scientific). The PCR mixture consisted of $10 \mu \mathrm{L}$ of Phire Plant Buffer $(2 \times), 40$ pmol of each primer pair (specific to the $s G F P$ gene and the GlyA gene of $A$. tumefaciens GV3101), $0.4 \mu \mathrm{L}$ of Phire Hot Start II DNA Pol and $0.5 \mu \mathrm{L}$ of diluted plant tissue. PCR conditions were $98^{\circ} \mathrm{C}$ for 5 min followed by 40 cycles at $98^{\circ} \mathrm{C}$ for $5 \mathrm{~s}, 60{ }^{\circ} \mathrm{C}$ for $5 \mathrm{~s}$ and $72{ }^{\circ} \mathrm{C}$ for $20 \mathrm{~s}$. Cycling was followed by a final incubation of $72{ }^{\circ} \mathrm{C}$ for $1 \mathrm{~min}$. PCR products were separated by gel electrophoresis based on the same protocol that was used for promoter PCR. Only $s G F P$-positive plants were selected for GFP fluorescence and RT-qPCR analysis.

\section{Verification of GFP fluorescence by UV light}

GFP fluorescence was verified with a FastGene ${ }^{\circledR}$ blue/green LED flashlight (FG-11; NIPPON Genetics, Tokyo, Japan), which was used to irradiate (excitation: $489 \mathrm{~nm}$; emission: $520 \mathrm{~nm}$ ) leaves and fruit at the mature red ripening stage (about three days after agroinjection) at a distance of $\sim 10 \mathrm{~cm}$ from each organ in the dark. To photograph the irradiated leaves, a yellow UV filter (NIPPON Genetics) was mounted to the camera (Nikon Coolpix B500, Tokyo, Japan) lens to filter out blue light, and to allow GFP fluorescence to be visualized. Fluorescence was also verified in controls at the same time. The location of GFP fluorescence was visually assessed and confirmed. Three controls were used for both methods at the same time as the agroinjection into ripe fruits and leaves using infiltration solution: (a) without any A. tumefaciens; (b) A. tumefaciens without any plasmid; (c) A. tumefaciens with a constitutive promoter (CaMV$35 \mathrm{~S})+s G F P$ in the plasmid.

\section{Quantification of sGFP expression by real-time PCR}

After confirming the possible presence of the $s G F P$ gene using UV fluorescence, tomato fruits and tobacco leaves (two per plant; 20 plants/line) showing fluorescence following UV light detection were picked after $3 \mathrm{~d}$. To measure sGFP intensity, RT-qPCR was used (Wang et al. 2004). Total RNA was isolated using Direct-zol ${ }^{\mathrm{TM}}$ (Zymo Research, Irvine, CA, USA) with TRIzol reagent based on the manufacturer's protocol. After purifying total RNA, three quality control methods were applied: 1) microcapillary electrophoresis with an Implen n50 spectrophotometer (Implen, Munich, Germany) for preliminary quantification; 2) agarose gel electrophoresis to assess total RNA degradation and potential contamination; 3) Agilent Bioanalyzer 2100 system (Agilent Technologies, Santa Clara, CA, USA) to check the quality and quantity of total RNA. cDNA was amplified from $120 \mathrm{ng}$ of total RNA with reverse transcription using the FIREScript RT cDNA Synthesis MIX (Solis BioDyne, Tartu, Estonia). qPCR was performed with the $5 \times$ HOT FIREPol EvaGreen qPCR Supermix (Solis BioDyne) on the ABI 7300 real-time PCR system (ThermoFischer Scientific) to detect the intensity of $s G F P$ expression. Specific primers (Suppl. Table 1) for RT-qPCR were used to detect $s G F P$ and normalizing (reference) genes (MtGAPDH: At1g13440, FvGAPDH: ID07104 and NbGAPDH: At1g12900) which were selected based on the stability of housekeeping gene expression level (Expósito-Rodríguez et al. 2008; Liu et al. 2012, 2020). In the RT-qPCR analysis, we used the $2^{-\Delta \Delta C t}$ method to quantify the relative changes in gene expression (Livak and Schmittgen 2001). To compare the intensity of $s G F P$ gene expression between the positive control (CaMV35S::sGFP) and promoter deletion line::sGFP constructs, gene expression logarithmic fold change (log2LFC) was calculated. The $2^{-\Delta \Delta C t}$ method and $\log 2 \mathrm{LFC}$ were calculated by HTqPCR v3.11 (Dvinge and Bertone 2009) in R software (Gentleman et al. 2004; Huber et al. 2015). The Student's $t$ test was performed using $\Delta \Delta \mathrm{Ct}$ values, and a $p$-value less than 0.05 was considered to be significant. Statistical analyses were conducted in GraphPad Prism 9.0 (GraphPad Software, San Diego, CA, USA). Results were exported into Microsoft Excel 365. 


\section{Results}

\section{Promoter sequence analysis}

After comparing of results from JASPAR2020 and PLACE 30.0 data, various putative TFs and CREs were examined in the promoter sequences of MtSPR1-like2, FvSPR1-like2, FvSPR1-like1, AtSPR1-like2, MtSPT, FvSPT and AtSPT genes. We identified 222, 364, 117, 186, 323, 473, and 484 TFBS and 473, 645, 248, 30, 548, 733, and 719 CREs in the promoter sequences of MtSPRI-like2, FvSPRI-like2, FvSPR1-like1, AtSPR1-like2, MtSPT, FvSPT and AtSPT genes, respectively (TFs: Suppl. Table 2; CREs: Suppl. Table 4).

We compared the different promoter regions (TF and CREs) related to flowering, fruit development and ripening in tomato, A. thaliana and $F$. vesca (Suppl. Table 2, Suppl. Table 5). Table 1 shows the frequency of TFBS in the promoter sequences that play a role in flowering and fruit ripening. There were 16, 25, 7, 5, 34, 24 and 29 TFBS in the promoter sequences of MtSPRI-like2, FvSPRI-like2, FvSPR1-like1, AtSPR1-like2, MtSPT, FvSPT and AtSPT genes, respectively (Table 1).

Table 2 shows the frequency of CREs in the promoter sequences that played a role in flowering and fruit ripening. There were 11, 25, 6, 1, 27, 26 and 16 CREs in the promoter sequences of MtSPRI-like2, FvSPRl-like2, FvSPR1-like1, AtSPR1-like2, MtSPT, FvSPT and AtSPT genes, respectively (Table 2). Based on the PLACE 30.0 database, CREs that were regulated by auxin, ethylene, $\mathrm{GA}_{3}$ and cytokinin were classification. We identified 1, 8 and 1 CREs that were promoted by ethylene, auxin and $\mathrm{GA}_{3}$, respectively. Cytokinin did not promote CREs in these promoter regions.
Using the UV lamp, GFP fluorescence was only detected in the leaves of FvSPR2000::pGWB604, FvSPT 1000::pGWB604, FvSPT2000::pGWB604, FvSPT3000::pGWB604 and CaMV35S::sGFP (pGWB405) tobacco lines (Suppl. Figure 1f, 1 h, 1i, 1j, 1c), and in the green fruit of FvSPR2000::pGWB604, FvSPT2000::pGWB604, FvSPT3000::pGWB604 and CaMV35S::sGFP (pGWB405) Micro-Tom tomato lines (Suppl. Figure 2c, e, f, b).

Using RT-qPCR, the $s G F P$ gene was detected and its expression intensity was measured in the fruits of MicroTom tomato and leaves of tobacco plants. In tobacco leaves, the intensity of $s G F P$ gene expression (RQ) was 0.072 , 0.006, 0.099 and 2.532 in the FvSPR2000::pGWB604, FvSPT1000::pGWB604, FvSPT2000::pGWB604 and FvSPT3000::pGWB604 lines, respectively, based on $\Delta \Delta \mathrm{Ct}$ values (Suppl. Table 6). The expression logarithmic fold change (LFC) was $-3.8,-7.29,-3.33$ and 1.34 in the FvSPR2000::pGWB604, FvSPT1000::pGWB604, FvSPT2000::pGWB604 and FvSPT3000::pGWB604 lines, respectively based on a comparison with $s G F P$ expression intensity of CaMV35S::sGFP as the positive control (Suppl. Table 6; Fig. 1).

In Micro-Tom tomato fruits, $s G F P$ gene expression intensity was $0.026,0.024$ and 1.028 in the FvSPR2000::pGWB604, FvSPT2000::pGWB604 and FvSPT3000::pGWB604 lines, respectively based on the Ct values (Suppl. Table 6). Expression LFC was -5.28, -5.36 and 0.04 in the FvSPR2000::pGWB604, FvSPT2000::pGWB604 and FvSPT3000::pGWB604 lines, respectively (Suppl. Table 6; Fig. 2) based on a comparison with $s G F P$ expression intensity of CaMV35S::sGFP as the positive control.
Fig. 1 LFC of $s G F P$ in tobacco leaves (control: CaMV35S::sGFP; sample size: 20 measurements per vector construct, total: 80 measurements with three biological replicates). Error bars: standard deviation. * Significant differences compared with the control (Student's $t$-test: $\mathrm{t}(38)=12.96$; $\mathrm{t}(38)=27.51 ; \mathrm{t}(38)=10.17$; $\mathrm{t}(38)=4.38, p<0.05)$. Also see Suppl. Table 6

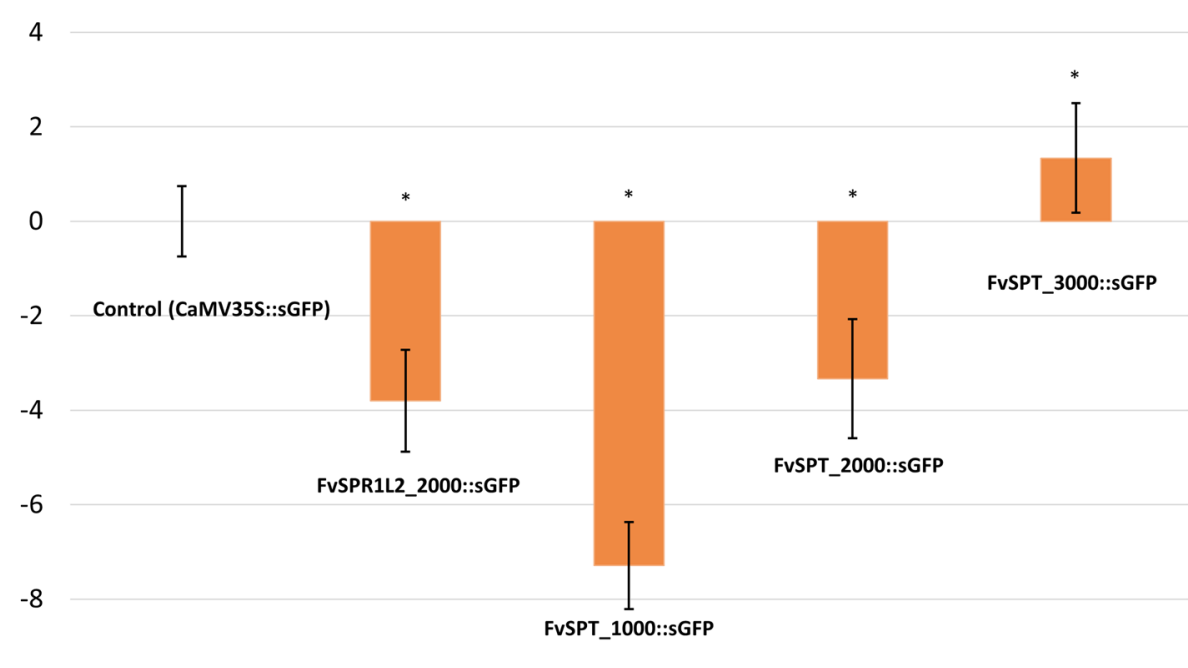


Table 1 Frequency of TFBS which play a role in flowering and ripening processes (based on Suppl. Table 3)

\begin{tabular}{|c|c|c|c|c|c|c|c|}
\hline \multirow[t]{2}{*}{ TFBS } & \multicolumn{7}{|l|}{ Frequency } \\
\hline & MtSPRI-like2 & FvSPR1-like1 & $F \vee S P R 1-l i k e 2$ & AtSPR1-like2 & $M t S P T$ & $F v S P T$ & $A t S P T$ \\
\hline ARF1 & & 1 & & & & & \\
\hline ARF2 & 2 & 1 & 1 & & 1 & & 2 \\
\hline ARF34 & & & & & & & 1 \\
\hline ARF5 & & 1 & & & & & \\
\hline ARF8 & & 1 & & & & & \\
\hline ARR10 & & 4 & 2 & & 3 & 1 & 1 \\
\hline ARR11 & & & 1 & & 2 & & \\
\hline ARR14 & & & & & 2 & & \\
\hline ARR18 & & & & & 1 & & \\
\hline ARR2 & 1 & & & & 1 & & \\
\hline ATHB15 & & & & & & & 1 \\
\hline ATHB20 & & 1 & & & 1 & & 1 \\
\hline ATHB23 & 1 & 1 & & & 6 & 2 & 2 \\
\hline ATHB53 & 1 & 1 & & & 1 & & 2 \\
\hline BEE2 & & & & & & 2 & 2 \\
\hline CAMTA1 & & 1 & & & & & \\
\hline CMTA3 & & 2 & & & & & 1 \\
\hline DREB26 & & & & & & 1 & \\
\hline EDT1 & & & & & 2 & 1 & \\
\hline ERF13 & & & & & & 1 & \\
\hline FaEOBII & & & & & & 1 & \\
\hline HAT2 & 1 & 1 & & 1 & 1 & 2 & 2 \\
\hline KAN1 & 1 & 4 & 2 & 2 & 4 & 2 & 3 \\
\hline KUA1 & & & & & 2 & & \\
\hline MYB124 & 1 & & & & & & 1 \\
\hline MYB59 & & 1 & & & 1 & 1 & 1 \\
\hline MYB73 & & 1 & & & & & \\
\hline OBP3 & & 1 & & & & & \\
\hline OsRR22 & & & & & 1 & & \\
\hline PIF5 & 1 & & & & 1 & 1 & 1 \\
\hline RVE1 & & 1 & & & & & \\
\hline SGR5 & & & & & & & 1 \\
\hline SPT & & & & & & 7 & 2 \\
\hline TGA1A & 1 & & 1 & 1 & & & 1 \\
\hline TGA2 & 1 & & & 1 & & & \\
\hline WRKY25 & 2 & 1 & & & 2 & & 2 \\
\hline WRKY8 & 3 & 1 & & & 2 & 2 & 2 \\
\hline
\end{tabular}

Compared to the control (CaMV35S::sGFP), FvSPR2000::pGWB604, FvSPT1000::pGWB604 and FvSPT2000::pGWB604 $\Delta \Delta$ Ct values were significantly different $(p \leq 0.05)$, while FvSPT3000::pGWB604 $\Delta \Delta \mathrm{Ct}$ values were significantly different $(p \leq 0.05)$ for tobacco leaves but not for tomato fruit (Suppl. Table 6).

\section{Discussion}

This research focused on the promoter region of $F v S P R 1$ like 2 and $F v S P T$ genes, which play an important role in cell development, flowering, and fruit development (Nakajima et al. 2004; Reyes-Olalde et al. 2017b; Hidvégi et al. 2020). Transient expression using agroinfiltration has limitations, such as the exclusive expressed of the marker gene ( $s G F P$ ) in the infiltrated area, while components of the expression cassette (vector construction) and strain or density of the Agrobacterium culture might affect the efficiency of gene 
Table 2 Frequency of $c i s$ regulatory elements (CREs) which play a role in flowering and ripening processes (based on Suppl. Table 5)

\begin{tabular}{|c|c|c|c|c|c|c|c|}
\hline \multirow[t]{2}{*}{ CREs } & \multicolumn{7}{|l|}{ Frequency } \\
\hline & MtSPR1-like2 & FvSPR1-like2 & FvSPR1-like1 & AtSPR1-like2 & $F v S P T$ & $A t S P T$ & $M t S P T$ \\
\hline Arfat & & 1 & & & 3 & 2 & \\
\hline Asf1motifcamv & 2 & 5 & 1 & & 3 & 4 & 1 \\
\hline Auxretga1gmgh3 & & 1 & 1 & & 1 & & \\
\hline Cacgcaatgmgh3 & & & & & & & 1 \\
\hline Cargatconsensus & & 2 & & & & & \\
\hline Catatggmsaur & & & & & & 6 & 2 \\
\hline Crtdrehvcbf2 & & 2 & & & & & \\
\hline D4gmaux 28 & & & & & 1 & & \\
\hline Erelee4 & 2 & 2 & 1 & & & 1 & 4 \\
\hline Gare1osrep1 & & & & & & & 1 \\
\hline Gareat & 2 & 6 & 3 & & & 3 & 2 \\
\hline Ntbbf1arrolb & 2 & 3 & 1 & & 9 & 4 & 4 \\
\hline Sebfconsstpr10a & & & & & 3 & 2 & \\
\hline Surecoreatsultr11 & 3 & 4 & & 1 & 8 & 4 & 1 \\
\hline
\end{tabular}

Fig. 2 LFC of $s G F P$ in MicroTom tomato fruit (control: CaMV35S::sGFP; sample size: 20 measurements per vector construct, total: 60 measurements with three biological replicates). Error bars: standard deviation. * Significant differences compared with the control (Student's $t$-test: $\mathrm{t}(38)=21.34$; $\mathrm{t}(38)=23.90 ; \mathrm{t}(38)=0.13$, $p<0.05)$. Also see Suppl. Table 6

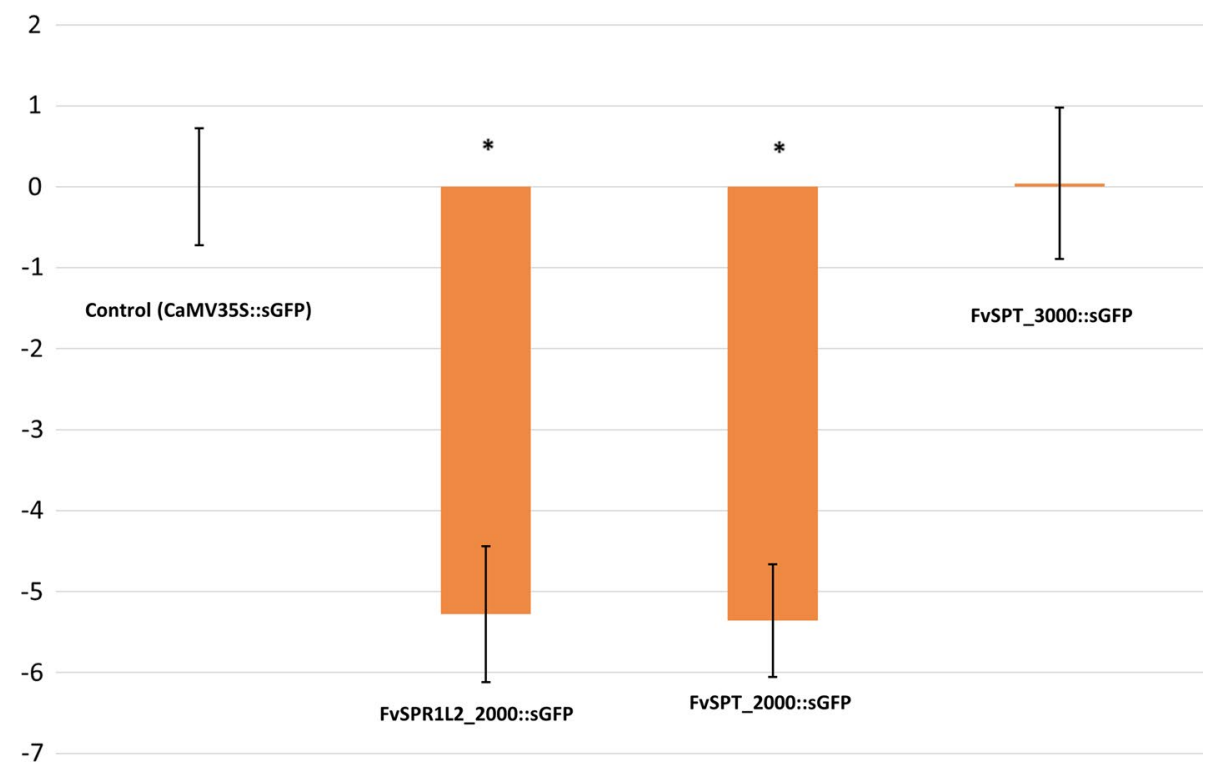

expression (Tyurin et al. 2020). The JASPAR2020 TFBS database has 572 profiles that include different classes and families of TFs in plants based on TF DNA-binding preferences, modeled as position weight matrices (Stormo 2013).

Fruit ripening in strawberry and tomato are controlled by ethylene and can be characterized by their color, ranging from green (unripe) to red (ripe) (Tisza et al. 2010; Li et al. 2017). Auxins retard fruit ripening, and an optimal ethyleneauxin balance can regulate the fruit ripening period ( $\mathrm{Su}$ et al. 2015). We identified the promoters of the FvSPRI-like 2 and FvSPT genes: ARF1 (Ellis et al. 2005), ARF2 (Zhang et al. 2014), ARF34 (Majer et al. 2012), ARF5 (Vidaurre et al. 2007), ARF8 (Nagpal et al. 2005), ATHB15 (Prigge et al. 2005), ATHB20 (Mattsson et al. 2003), ATHB53 (Son et al. 2004), CAMTA1 (Bouché et al. 2002), EDT1 (Cai et al.
2015), HAT2 (Sawa et al. 2002), KAN1 (Hawker and Bowman 2004), KUA1 (Lu et al. 2014), MYB124 (Chen et al. 2015), MYB73 (Kim et al. 2013), OBP3 (Kang et al. 2003), RVE1 (Meissner et al. 2013), SGR5 (Morita et al. 2006), TGA1A (Pascuzzi et al. 1998) and TGA2 (Johnson et al. 2003) sites. Auxin response factors (ARFs) can bind specifically to the DNA sequence 5'-TGTCTC-3' found in auxinresponsive promoter elements (AuxREs; Majer et al. 2012). We identified ARFAT and SURECOREATSULTR 11 CREs that contain ARF binding sequences (Maruyama-Nakashita et al. 2005) on the promoters of the FvSPRI-like2 and $F v S P T$ genes. The AUXRETGA1GMGH3 CRE is a strong binding site for proteins to the AuxRE which regulates ARFs (Guilfoyle et al. 1998). 
The AGL42 (Dorca-Fornell et al. 2011), ARR2 (Weirauch et al. 2014), CMTA3 (Bouché et al. 2002), DREB26 (Krishnaswamy et al. 2011), ERF13 (OñateSánchez and Singh 2002), KUA1 (Lu et al. 2014), MYB59 (Li et al. 2006), PIF5 (Khanna et al. 2007), WRKY25 (Li et al. 2011) and WRKY8 (Chen et al. 2013) sites are located on the promoter of FvSPRl-like 2 and FvSPT genes. The AGL42 site, which is a MADS-box TF, is involved in the control of flowering time, and promotes flowering at the shoot apical and axillary meristems. Genes that are controlled by AGL42 are regularly expressed in the leaves, flower buds, petals and abscission zone of $A$. thaliana flowers and siliques (Dorca-Fornell et al. 2011). We identified AGL42 on the promoters of MtSPRI-like2, AtSPRI-like2, MtSPT, FvSPT and AtSPT genes.

ARR1 (Sakai et al. 2001), ATHB34 (Henriksson et al. 2005), BEE2 (Friedrichsen et al. 2002), FUS3 (Tsuchiya et al. 2004), MYB33 (Gocal et al. 2001), MYR2 (Zhao et al. 2011), SOC1 (Lee et al. 2008), SRM1 (Wang et al. 2015) and STZ (Mittler et al. 2006) TFs were found in the promoters of the FvSPRI-like 2 and FvSPT genes. The GARE1OSREP1 CRE regulates the gibberellin-responsive element (GARE), including the MYB33 TFBS (Sutoh and Yamauchi 2003).

ARR10 (Hwang and Sheen 2001), ARR11 (Imamura et al. 2003), ARR14 (Mason et al. 2004), ARR18 (Liang et al. 2012) and OsRR22 (Tsai et al. 2012) were located on the promoters of FvSPRI-like 2 and FvSPT genes.

The FvSPR500::pGWB604 and FvSPR1000:pGWB604 constructs did not work in tobacco leaves, but FvSPR2000:pGWB604 did. FvSPR2000::pGWB604 also expressed the $s G F P$ gene in Micro-Tom fruit. We found ARF1, ARF2, ARF5 and ARF8 sites in the -1067 to -1059 bp region of the promoter deletion lines of the FvSPRI-like 2 gene. These sites were not in the -500 to $-1 \mathrm{bp}$ and -501 to $-1000 \mathrm{bp}$ regions. The ARF family of TFs play a role in ARFmediated auxin signaling in the maturation of reproductive organs (Liu et al. 2015), perhaps, explaining why FvSPR2000::pGWB604 was the only construct that induced $s G F P$ in tobacco leaves and tomato fruit. The FvSPT1000::pGWB604, FvSPT2000::pGWB604 and FvSPT3000::pGWB604 constructs worked in tobacco leaves, but FvSPT1000::pGWB604 did not work in Micro-Tom tomato fruit. The FvSPR500::pGWB604 construct did not work in Micro-Tom tomato fruit or in tobacco leaves. The FvSPR1000::pGWB604 construct had a lower $s G F P$ gene expression intensity than FvSPR2000::pGWB604. This differential expression may have been caused by MYB59, WRKY25 and WRKY8 sites, which are regulated by ethylene ( $\mathrm{Li}$ et al. 2006, 2011; Chen et al. 2013). The ethylene-auxin interaction might have a role in regulating the promoter of the FvSPR gene, as occurs in tomato where there is an antagonistic effect between ethylene and auxin during tomato fruit ripening ( $\mathrm{Li}$ et al. 2017). The FvSPR1000::pGWB604 construct does not have the MYB59, WRKY25 and WRKY 8 sites because these are only found between the -1256 and $-1248 \mathrm{bp},-1609$ to -1602 and -1610 to -1602 regions (Suppl. Table 2), respectively, which do not exist in the FvSPR2000::pGWB604 construct. The FvSPT1000::pGWB604, FvSPT2000::pGWB604 and FvSPT3000::pGWB604 constructs worked in tobacco leaves (Suppl. Figure 1), but the FvSPT1000::pGWB604 construct did not work in Micro-Tom tomato fruit (Suppl. Figure 2).

\section{Conclusion for future biology}

In our experiment, we reported CREs specific to various TFs in regions of putative $F v S P T$ and $F v S P R I$-like 2 genes by bioinformatic analysis. The promoter of the FvSPRIlike2 gene has the following: (1) MYB59, WRKY25 and WRKY8 TFs, which play a role in ethylene signaling; (2) ARF family of TFs, which play a role in ARF-mediated auxin signaling. The promoter of the FvSPT gene has the following: (1) ARR family of TFs, which play a role in cytokinin signaling; (2) ERF family of TFs, which play a role in ethylene signaling. The function and names of these sites and elements, as defined in JAPAR2020 and PLACE 30.0 databases, were also identified. The function of TFs and CREs were confirmed with promoter deletion lines and $s G F P$ reporter gene constructs in tobacco leaves or tomato fruit by agroinjection.

In recent years, the use of transgenic techniques has led to improvements in many plant species due to identification of a large number of genes. Molecular researchers have made efforts to isolate tissue-specific promoters to increase the added value of transgenes. Transcriptional regulation is a most important goal in the post-genomic era by understanding the transcriptional factors in the promoter regions. There are several databases about analyzing, identifying and characterizing promoters, which currently available from different plant species. With the analyzing progress of promoter and TFs that has been achieved in the agricultural sector through current biotechnological and bioinformatic techniques, might be open a new door to new tissue- and stage-specific promoters in new genetically modified (GM) cultivars.

Supplementary Information The online version contains supplementary material available at https://doi.org/10.1007/s42977-021-00089-x. 
Acknowledgements The research was financed by the Higher Education Institutional Excellence Program (NKFIH-1150-6/2019) of the Ministry of Innovation and Technology in Hungary, within the framework of the Biotechnology thematic program of the University of Debrecen, and that of Szent István University (NKFIH-1159-6/2019) and a grant from the Hungarian Research Fund K (101195) entitled "Functional analysis of genes and their promoters identified during the fruit ripening of strawberry".

Author contributions N.H. and E.K. designed the project and experiments. N.H., A.G. and A.W. carried out the experiments. N.H., A.G. and J.A.T.d.S. wrote the manuscript with support from A.W. and E.K. E.K and J.A.T.d.S. supervised the project. N.H. and A.G. established the RT-qPCR experiments. All authors saw and approved the final version of manuscript for submission.

Funding Open access funding provided by University of Debrecen.

\section{Declarations}

Conflicts of interest The authors declare no conflicts of interest regarding this paper.

Open Access This article is licensed under a Creative Commons Attribution 4.0 International License, which permits use, sharing, adaptation, distribution and reproduction in any medium or format, as long as you give appropriate credit to the original author(s) and the source, provide a link to the Creative Commons licence, and indicate if changes were made. The images or other third party material in this article are included in the article's Creative Commons licence, unless indicated otherwise in a credit line to the material. If material is not included in the article's Creative Commons licence and your intended use is not permitted by statutory regulation or exceeds the permitted use, you will need to obtain permission directly from the copyright holder. To view a copy of this licence, visit http://creativecommons.org/licenses/by/4.0/.

\section{References}

An J, Almasaud RA, Bouzayen M, Zouine M, Chervin C (2020) Auxin and ethylene regulation of fruit set. Plant Sci 292:110381. https:// doi.org/10.1016/j.plantsci.2019.110381

Bapat VA, Trivedi PK, Ghosh A, Sane VA, Ganapathi TR, Nath P (2010) Ripening of fleshy fruit: molecular insight and the role of ethylene. Biotechnol Adv 28:94-107. https://doi.org/10.1016/j. biotechadv.2009.10.002

Bergkessel M, Guthrie C (2013) Colony PCR. Methods Enzymol 529:299-309. https://doi.org/10.1016/B978-0-12-418687-3. $00025-2$

Bertani G (1951) Studies on lysogenesis I. the mode of phage liberation by lysogenic Escherichia coli. J Bacteriol. 62:293

Bichet A, Desnos T, Turner S, Grandjean O, Höfte H (2001) BOTERO1 is required for normal orientation of cortical microtubules and anisotropic cell expansion in Arabidopsis. Plant J 25:137-148. https://doi.org/10.1111/j.1365-313X.2001.00946.X

Bouché N, Scharlat A, Snedden W, Bouchez D, Fromm H (2002) A novel family of calmodulin-binding transcription activators in multicellular organisms. J Biol Chem 277:21851-21861. https:// doi.org/10.1074/jbc.M200268200

Burk DH, Ye ZH (2002) Alteration of oriented deposition of cellulose microfibrils by mutation of a katanin-like microtubule-severing protein. Plant Cell 14:2145-2160. https://doi.org/10.1105/tpc. 003947

Cai XT, Xu P, Wang Y, Xiang CB (2015) Activated expression of AtEDT1/HDG11 promotes lateral root formation in Arabidopsis mutant $e d t 1$ by upregulating jasmonate biosynthesis. J Integr Plant Biol 57:1017-1030. https://doi.org/10.1111/jipb.12347

Chen L, Zhang L, Li D, Wang F, Yu D (2013) WRKY8 transcription factor functions in the TMV-cg defense response by mediating both abscisic acid and ethylene signaling in Arabidopsis. Proc Natl Acad Sci USA 110:E1963-E1971. https://doi.org/10.1073/ pnas. 1221347110

Chen Q, Liu Y, Maere S, Lee E, Van Isterdael G, Xie Z, Xuan W, Lucas J, Vassileva V, Kitakura S, Marhavý P, Wabnik K, Geldner N, Benková E, Le J, Fukaki H, Grotewold E, Li C, Friml J, Sack F, Beeckman T, Vanneste S (2015) A coherent transcriptional feedforward motif model for mediating auxin-sensitive PIN3 expression during lateral root development. Nature Commun 6:8821. https://doi.org/10.1038/ncomms9821

Corrado G, Karali M (2009) Inducible gene expression systems and plant biotechnology. Biotechnol Adv 27:733-743. https://doi.org/ 10.1016/j.biotechadv.2009.05.006

Dorca-Fornell C, Gregis V, Grandi V, Coupland G, Colombo L, Kater MM (2011) The Arabidopsis SOC1-like genes AGL42, AGL71 and $A G L 72$ promote flowering in the shoot apical and axillary meristems. Plant J 67:1006-1017. https://doi.org/10.1111/j.1365313X.2011.04653.X

Dvinge H, Bertone P (2009) HTqPCR: high-throughput analysis and visualization of quantitative real-time PCR data in R. Bioinformatics 25:3325-3326. https://doi.org/10.1093/bioinformatics/ btp578

Ellis CM, Nagpal P, Young JC, Hagen G, Guilfoyle TJ, Reed JW (2005) AUXIN RESPONSE FACTOR1 and AUXIN RESPONSE FACTOR2 regulate senescence and floral organ abscission in Arabidopsis thaliana. Development 132:4563-4574. https://doi. org/10.1242/dev.02012

Expósito-Rodríguez M, Borges AA, Borges-Pérez A, Pérez JA (2008) Selection of internal control genes for quantitative realtime RT-PCR studies during tomato development process. BMC Plant Biol 8:131. https://doi.org/10.1186/1471-2229-8-131

Fornes O, Castro-Mondragon JA, Khan A, van der Lee R, Zhang X, Richmond PA, Modi BP, Correard S, Gheorghe M, Baranašić D, Santana-Garcia W, Tan G, Chèneby J, Ballester B, Parcy F, Sandelin A, Lenhard B, Wasserman WW, Mathelier A (2020) JASPAR 2020: update of the open-access database of transcription factor binding profiles. Nucl Acids Res 48:D87-D92. https:// doi.org/10.1093/nar/gkz1001

Friedrichsen DM, Nemhauser J, Muramitsu T, Maloof JN, Alonso J, Ecker JR, Furuya M, Chory J (2002) Three redundant brassinosteroid early response genes encode putative bHLH transcription factors required for normal growth. Genetics 162:1445-1456

Furutani I, Watanabe Y, Prieto R, Masukawa M, Suzuki K, Naoi K, Thitamadee S, Shikanai T, Hashimoto T (2000) The SPIRAL genes are required for directional control of cell elongation in Arabidopsis thaliana. Development 127:4443-4453

Gentleman RC, Carey VJ, Bates DM, Bolstad B, Dettling M, Dudoit S, Ellis B, Gautier L, Ge Y, Gentry J, Hornik K, Hothorn T, Huber W, Iacus S, Irizarry R, Leisch F, Li C, Maechler M, Rossini AJ, Sawitzki G, Smith C, Smyth G, Tierney L, Yang JY, Zhang J (2004) Bioconductor: open software development for computational biology and bioinformatics. Genome Biol 5:R80. https://doi.org/10.1186/gb-2004-5-10-r80

Gocal GFW, Sheldon CC, Gubler F, Moritz T, Bagnall DJ, MacMillan CP, Li SF, Parish RW, Dennis ES, Weigel D, King RW (2001) GAMYB-like genes, flowering, and gibberellin signalling in Arabidopsis. Plant Physiol 127:1682-1693. https://doi.org/ 10.1104/pp.010442 
Guilfoyle T, Hagen G, Ulmasov T, Murfett J (1998) How does auxin turn on genes? Plant Physiol 118:341-347. https://doi.org/10. 1104/pp.118.2.341

Hawker NP, Bowman JL (2004) Roles for class III HD-Zip and KANADI genes in Arabidopsis root development. Plant Physiol 135:2261-2270. https://doi.org/10.1104/pp.104.040196

Henriksson E, Olsson AS, Johannesson H, Johansson H, Hanson J, Engström P, Söderman E (2005) Homeodomain leucine zipper class I genes in Arabidopsis. Expression patterns and phylogenetic relationships. Plant Physiol 139:509-518. https://doi.org/ 10.1104/pp.105.063461

Hidvégi N, Gulyás A, Teixeira da Silva JA, Posta K, Kiss E (2020) Complementation of wild strawberry (Fragaria vesca L.) SPATULA (FvSPT) and SPIRAL (FvSPR) genes in Arabidopsis thaliana. Columella 7:23-34. https://doi.org/10.18380/SZIE. COLUM.2020.7.1.23

Higo K, Ugawa Y, Iwamoto M, Korenagam T (1999) Plant cis-acting regulatory DNA elements (PLACE) database:1999. Nucl Acids Res 27:297-300. https://doi.org/10.1093/nar/27.1.297

Hoshikawa K, Fujita S, Renhu N, Ezura K, Yamamoto T, Nonaka S, Ezura H, Miura K (2019) Efficient transient protein expression in tomato cultivars and wild species using agroinfiltration-mediated high expression system. Plant Cell Rep 38:75-84. https:// doi.org/10.1007/s00299-018-2350-1

Huber W, Carey VJ, Gentleman R, Anders S, Carlson M, Carvalho BS, Bravo HC, Davis S, Gatto L, Girke T, Gottardo R, Hahne F, Hansen KD, Irizarry RA, Lawrence M, Love MI, MacDonald J, Obenchain V, Oleś AK, Pagès H, Reyes A, Shannon P, Smyth GK, Tenenbaum D, Waldron L, Morgan M (2015) Orchestrating high-throughput genomic analysis with Bioconductor. Nat Methods 12:115-121. https://doi.org/10.1038/nmeth.3252

Hwang I, Sheen J (2001) Two-component circuitry in Arabidopsis cytokinin signal transduction. Nature 413:383-389. https://doi. org/10.1038/35096500

Imamura A, Kiba T, Tajima Y, Yamashino T, Mizuno T (2003) In vivo and in vitro characterization of the ARR11 response regulator implicated in the His-to-Asp phosphorelay signal transduction in Arabidopsis thaliana. Plant Cell Physiol 44:122-131. https://doi. org/10.1093/pcp/pcg014

Johnson C, Boden E, Arias J (2003) Salicylic acid and NPR1 induce the recruitment of trans-activating TGA factors to a defense gene promoter in Arabidopsis. Plant Cell 15:1846-1858. https://doi. org/10.1105/tpc.012211

Kang HG, Foley RC, Oñate-Sánchez L, Lin C, Singh KB (2003) Target genes for OBP3, a Dof transcription factor, include novel basic helix-loop-helix domain proteins inducible by salicylic acid. Plant J 35:362-372. https://doi.org/10.1046/j.1365-313X.2003.01812.x

Khanna R, Shen Y, Marion CM, Tsuchisaka A, Theologis A, Schäfer E, Quail PH (2007) The basic helix-loop-helix transcription factor PIF5 acts on ethylene biosynthesis and phytochrome signaling by distinct mechanisms. Plant Cell 19:3915-3929. https://doi.org/10. $1105 /$ tpc. 107.051508

Kim WC, Kim JY, Ko JH, Kim J, Han KH (2013) Transcription factor MYB46 is an obligate component of the transcriptional regulatory complex for functional expression of secondary wall-associated cellulose synthases in Arabidopsis thaliana. J Plant Physiol 170:1374-1378. https://doi.org/10.1016/j.jplph.2013.04.012

Krishnaswamy S, Verma S, Rahman MH, Kav NNV (2011) Functional characterization of four APETALA2-family genes (RAP2.6, RAP2.6L, DREB19 and DREB26) in Arabidopsis. Plant Mol Biol 75:107-127. https://doi.org/10.1007/s11103-010-9711-7

Kumar R, Khurana A, Sharma AK (2014) Role of plant hormones andtheir interplay in development and ripening of fleshy fruits. $J$ Exp Bot 65:4561-4575. https://doi.org/10.1093/jxb/eru277
Lee J, Oh M, Park H, Lee I (2008) SOC1 translocated to the nucleus by interaction with AGL24 directly regulates $L E A F Y$. Plant J 55:832-843. https://doi.org/10.1111/j.1365-313X.2008.03552.x

Li J, Li X, Guo L, Lu F, Feng X, He K, Wei L, Chen Z, Qu LJ, Gu H (2006) A subgroup of $M Y B$ transcription factor genes undergoes highly conserved alternative splicing in Arabidopsis and rice. $\mathrm{J}$ Exp Bot 57:1263-1273. https://doi.org/10.1093/jxb/erj094

Li J, Tao X, Bu J, Ying T, Mao L, Luo Z (2017) Global transcriptome profiling analysis of ethylene-auxin interaction during tomato fruit ripening. Postharvest Biol Technol 130:28-38. https://doi.org/10. 1016/j.postharvbio.2017.03.021

Li S, Fu Q, Chen L, Huang W, Yu D (2011) Arabidopsis thaliana WRKY25, WRKY26, and WRKY33 coordinate induction of plant thermotolerance. Planta 233:1237-1252. https://doi.org/10.1007/ s00425-011-1375-2

Liang Y, Wang X, Hong S, Li Y, Zuo J (2012) Deletion of the initial 45 residues of ARR18 induces cytokinin response in Arabidopsis. J Genet Genomics 39:37-46. https://doi.org/10.1016/j.jgg.2011. 12.004

Liu D, Shi L, Han C, Yu J, Li D, Zhang Y (2012) Validation of reference genes for gene expression studies in virus-infected Nicotiana benthamiana using quantitative real-time. PLoS ONE 7:e46451. https://doi.org/10.1371/journal.pone.0046451

Liu D, Huang X, Lin Y, Wang X, Yan Z, Wang Q, Ding J, Gu T, Li Y (2020) Identification of reference genes for transcript normalization in various tissue types and seedlings subjected to different abiotic stresses of woodland strawberry Fragaria vesca. Sci Hortic 261:108840. https://doi.org/10.1016/j.scienta.2019.108840

Liu K, Yuan C, Li H, Lin W, Yang Y, Shen C, Zheng X (2015) Genomewide identification and characterization of auxin response factor (ARF) family genes related to flower and fruit development in papaya (Carica papaya L.). BMC Genomics 16:901. https://doi. org/10.1186/s12864-015-2182-0

Livak KJ, Schmittgen TD (2001) Analysis of relative gene expression data using real-time quantitative PCR and the $2^{-\Delta \Delta C T}$ method. Methods 25:402-408. https://doi.org/10.1006/meth.2001.1262

Lu D, Wang T, Persson S, Mueller-Roeber B, Schippers JH (2014) Transcriptional control of ROS homeostasis by KUODA1 regulates cell expansion during leaf development. Nature Commun 5:3767. https://doi.org/10.1038/ncomms4767

Majer C, Xu C, Berendzen KW, Hochholdinger F (2012) Molecular interactions of rootless concerning crown and seminal roots, a lob domain protein regulating shoot-borne root initiation in maize (Zea mays L.). Philos Trans R Soc 367:1542-2155. https://doi.org/10.1098/rstb.2011.0238

Maruyama-Nakashita A, Nakamura Y, Watanabe-Takahashi A, Inoue E, Yamaya T, Takahashi H (2005) Identification of a novel cisacting element conferring sulfur deficiency response in Arabidopsis roots. Plant J 42:305-314. https://doi.org/10.1111/j. 1365-313X.2005.02363.x

Mason MG, Li J, Mathews DE, Kieber JJ, Schaller GE (2004) Type$\mathrm{B}$ response regulators display overlapping expression patterns in Arabidopsis. Plant Physiol 135:927-937. https://doi.org/10. 1104/pp.103.038109

Mattsson J, Ckurshumova W, Berleth T (2003) Auxin signaling in Arabidopsis leaf vascular development. Plant Physiol 131:1327-1339. https://doi.org/10.1104/pp.013623

Meissner M, Orsini E, Ruschhaupt M, Melchinger AE, Hincha DK, Heyer AG (2013) Mapping quantitative trait loci for freezing tolerance in a recombinant inbred line population of Arabidopsis thaliana accessions tenela and C24 reveals REVEILLE1 as negative regulator of cold acclimation. Plant Cell Environ 36:1256-1267. https://doi.org/10.1111/pce.12054

Meshi T, Iwabuchi M (1995) Plant transcription factors. Plant Cell Physiol 36:1405-1420. https://doi.org/10.1093/oxfordjournals. pcp.a078903 
Mittler R, Kim Y, Song L, Coutu J, Coutu A, Ciftci-Yilmaz S, Lee H, Stevenson B, Zhu JK (2006) Gain- and loss-of-function mutations in Zat10 enhance the tolerance of plants to abiotic stress. FEBS Lett 580:6537-6542. https://doi.org/10.1016/j.febslet. 2006.11.002

Morita MT, Sakaguchi K, Kiyose SI, Taira K, Kato T, Nakamura M, Tasaka M (2006) A C2H2-type zinc finger protein, SGR5, is involved in early events of gravitropism in Arabidopsis inflorescence stems. Plant J 47:619-628. https://doi.org/10.1111/j. 1365-313X.2006.02807.x

Moubayidin L, Ostergaard L (2014) Dynamic control of auxin distribution imposes a bilateral-to-radial symmetry switch during gynoecium development. Curr Biol CB 24:2743-2748. https:// doi.org/10.1016/j.cub.2014.09.080

Nagpal P, Ellis CM, Weber H, Ploense SE, Barkawi LS, Guilfoyle TJ, Hagen G, Alonso JM, Cohen JD, Farmer EE, Ecker JR, Reed JW (2005) Auxin response factors ARF6 andARF8 promote jasmonic acid production and flower maturation. Development 132:4107-4118. https://doi.org/10.1242/dev.01955

Nakagawa T, Kurose T, Hino T, Tanaka K, Kawamukai M, Niwa Y, Toyooka K, Matsuoka K, Jinbo T, Kimura T (2007) Development of series of gateway binary vectors, pGWBs, for realizing efficient construction of fusion genes for plant transformation. J Biosci Bioeng 104:34-41. https://doi.org/10.1263/jbb.104.34

Nakajima K, Furutani I, Tachimoto H, Matsubara H, Hashimoto T (2004) SPIRAL1 encodes a plant-specific microtubule-localized protein required for directional control of rapidly expanding Arabidopsis cells. Plant Cell 16:1178-1190. https://doi.org/10. 1105/tpc.017830

Niwa Y (2003) A synthetic green fluorescent protein gene for plant biotechnology. Plant Biotechnol 20:1-11. https://doi.org/10. 5511/plantbiotechnology.20.1

Norkunas K, Harding R, Dale J, Dugdale B (2018) Improving agroinfiltration-based transient gene expression in Nicotiana benthamiana. Plant Methods 14:71. https://doi.org/10.1186/s13007-018-0343-2

Oñate-Sánchez L, Singh KB (2002) Identification of Arabidopsis ethylene-responsive element binding factors with distinct induction kinetics after pathogen infection. Plant Physiol 128:1313-1322. https://doi.org/10.1104/pp.010862

Pascuzzi P, Hamilton D, Bodily K, Arias J (1998) Auxin-induced stress potentiates trans-activation by a conserved plant basic/leucinezipper factor. J Biol Chem 273:26631-26637. https://doi.org/10. $1074 / j b c .273 .41 .26631$

Prigge MJ, Otsuga D, Alonso JM, Ecker JR, Drews GN, Clark SE (2005) Class III homeodomain-leucine zipper gene family members have overlapping, antagonistic, and distinct roles in Arabidopsis development. Plant Cell 17:61-76. https://doi.org/10.1105/ tpc. 104.026161

Reed J, Osbourn A (2018) Engineering terpenoid production through transient expression in Nicotiana benthamiana. Plant Cell Rep 37:1431-1441. https://doi.org/10.1007/s00299-018-2296-3

Reyes-Olalde JI, Zúñiga-Mayo VM, Marsch-Martínez N, de Folter S (2017a) Synergistic relationship between auxin and cytokinin in the ovary and the participation of the transcription factor SPATULA. Plant Signal Behav 12:e1376158. https://doi.org/10.1080/ 15592324.2017.1376158

Reyes-Olalde JI, Zúñiga-Mayo VM, Serwatowska J, Chavez Montes RA, Lozano-Sotomayor P, Herrera-Ubaldo H, Gonzalez-Aguilera KL, Ballester P, Ripoll JJ, Ezquer I, Paolo D, Heyl A, Colombo L, Yanofsky MF, Ferrandiz C, Marsch-Martinez N, de Folter S (2017b) The bHLH transcription factor SPATULA enables cytokinin signaling, and both activate auxin biosynthesis and transport genes at the medial domain of the gynoecium. PLoS Genet 13:e1006726. https://doi.org/10.1371/journal.pgen.1006726

Sakai H, Honma T, Aoyama T, Sato S, Kato T, Tabata S, Oka A (2001) ARR1, a transcription factor for genes immediately responsive to cytokinins. Science 294:1519-1521. https://doi.org/10.1126/ science. 1065201

Sambrook J, Fritsch EF, Maniatis T (1989) Molecular cloning: a laboratory manual (2nd ed). Cold Spring Harbor Laboratory Press, NY, USA.

Sawa S, Ohgishi M, Goda H, Higuchi K, Shimada Y, Yoshida S, Koshiba T (2002) The HAT2 gene, a member of the HD-Zip gene family, isolated as an auxin inducible gene by DNA microarray screening, affects auxin response in Arabidopsis. Plant J 32:10111022. https://doi.org/10.1046/j.1365-313X.2002.01488.x

Schuster C, Gaillochet C, Lohmann JU (2015) Arabidopsis HECATE genes function in phytohormone control during gynoecium development. Development 142:3343-3350. https://doi.org/10.1242/ dev. 120444

Singer K, Shiboleth YM, Li J, Tzfira T (2012) Formation of complex extrachromosomal T-DNA structures in Agrobacterium tumefaciens-infected plants. Plant Physiol 160:511-522. https://doi.org/ 10.1104/pp.112.200212

Son O, Cho HY, Kim MR, Lee H, Lee MS, Song E, Park JH, Nam KH, Chun JY, Kim HJ, Hong SK, Chung YY, Hur CG, Cho HT, Cheon CI (2004) Induction of a homeodomain-leucine zipper gene by auxin is inhibited by cytokinin in Arabidopsis roots. Biochem Biophys Res Commun 326:203-209. https://doi.org/10.1016/j. bbrc.2004.11.014

Stormo GD (2013) Modeling the specificity of protein-DNA interactions. Quant Biol 1:115-130. https://doi.org/10.1007/ s40484-013-0012-4

Su L, Diretto G, Purgatto E, Danoun S, Zouine M, Li Z, Roustan JP, Bouzayen M, Giuliano G, Chervin C (2015) Carotenoid accumulation during tomato fruitripening is modulated by the auxinethylene balance. BMC Plant Biol 15:114. https://doi.org/10.1186/ s12870-015-0495-4

Sutoh K, Yamauchi D (2003) Two cis-acting elements necessary and sufficient for gibberellin-upregulated proteinase expression in rice seeds. Plant J 34:635-645. https://doi.org/10.1046/j.1365-313X. 2003.01753.x

Swarbreck D, Wilks C, Lamesch P, Berardini TZ, Garcia-Hernandez M, Foerster H, Li D, Meyer T, Muller R, Ploetz L, Radenbaugh A, Singh S, Swing V, Tissier C, Zhang P, Huala E (2007) The Arabidopsis Information Resource (TAIR): gene structure and function annotation. Nucl Acids Res 36:D1009-D1014. https:// doi.org/10.1093/nar/gkm965

Tisza V, Kovács L, Balogh A, Heszky L, Kiss E (2010) Characterization of FaSPT, a FaSPT gene encoding a bHLH transcriptional factor from the non-climacteric strawberry fruit. Plant Physiol Biochem 48:822-826. https://doi.org/10.1016/j.plaphy.2010.08. 001

Tsai YC, Weir NR, Hill K, Zhang W, Kim HJ, Shiu SH, Schaller GE, Kieber JJ (2012) Characterization of genes involved in cytokinin signaling and metabolism from rice. Plant Physiol 158:16661684. https://doi.org/10.1104/pp.111.192765

Tsuchiya Y, Nambara E, Naito S, McCourt P (2004) The FUS3 transcription factor functions through the epidermal regulator TTG1 during embryogenesis in Arabidopsis. Plant J 37:73-81. https:// doi.org/10.1046/j.1365-313X.2003.01939.x

Tyurin AA, Suhorukova AV, Kabardaeva KV, Goldenkova-Pavlova IV (2020) Transient gene expression is an effective experimental tool for the research into the fine mechanisms of plant gene function: advantages, limitations, and solutions. Plants 9:1187. https://doi. org/10.3390/plants9091187

Vidaurre DP, Ploense S, Krogan NT, Berleth T (2007) AMP1 and MP antagonistically regulate embryo and meristem development in Arabidopsis. Development 134:2561-2567. https://doi.org/10. 1242/dev.006759

Wang G, Gentry TJ, Grass G, Josephson K, Rensing C, Pepper IL (2004) Real-time PCR quantification of a green fluorescent 
protein-labeled, genetically engineered Pseudomonas putida strain during 2-chlorobenzoate degradation in soil. FEMS Microbiol Lett 233:307-314. https://doi.org/10.1111/j.1574-6968.2004. tb09497.x

Wang T, Tohge T, Ivakov A, Mueller-Roeber B, Fernie AR, Mutwil M, Schippers JH, Persson S (2015) Salt-related MYB1 coordinates abscisic acid biosynthesis and signaling during salt stress in Arabidopsis. Plant Physiol 169:1027-1041. https://doi.org/10. 1104/pp.15.00962

Weirauch MT, Yang A, Albu M, Cote AG, Montenegro-Montero A, Drewe P, Najafabadi HS, Lambert SA, Mann I, Cook K, Zheng H, Goity A, van Bakel H, Lozano JC, Galli M, Lewsey MG, Huang E, Mukherjee T, Chen X, Reece-Hoyes JS, Govindarajan S, Shaulsky G, Walhout AJM, Bouget FY, Ratsch G, Larrondo LF, Ecker JR, Hughes T (2014) Determination and inference of eukaryotic transcription factor sequence specificity. Cell 158:1431-1443. https://doi.org/10.1016/j.cell.2014.08.009

Zhang JY, He SB, Li L, Yang HQ (2014) Auxin inhibits stomatal development through MONOPTEROS repression of a mobile peptide gene STOMAGEN in mesophyll. Proc Natl Acad Sci USA 111:E3015-E3023. https://doi.org/10.1073/pnas.1400542111

Zhao C, Hanada A, Yamaguchi S, Kamiya Y, Beers EP (2011) The Arabidopsis Myb genes MYR1 and MYR2 are redundant negative regulators of flowering time under decreased light intensity. Plant J 66:502-515. https://doi.org/10.1111/j.1365-313X.2011.04508.x

Ziliotto F, Corso M, Rizzini FM, Rasori A, Botton A, Bonghi C (2012) Grape berry ripening delay induced by a pre-véraison NAA treatment is paralleled by a shift in the expression pattern of auxin- and ethylene-related genes. BMC Plant Biol 12:185. https://doi.org/ $10.1186 / 1471-2229-12-185$ 